\title{
3 Research Square

\section{Synergistic influence of education and marriage on the risk for cognition loss among the older people in China}

ning sun

Ningbo College of Health Sciences

Rangcheng Jia (D55437389@qq.com)

Institute of Health Service Research, Ningbo College of Health Sciences

Chunyan Guo

ningbo college of health sciences

Tongda Sun

nignbo college of health sciences

Xiaoxin Dong

ningbo college of health sciences

Long Li

Ningbo City College of Vocational Technology

Ping Yang

ningbo college of health sciences

Research article

Keywords: education, older people, marriage, senile dementia, severe cognitive impairment

Posted Date: December 15th, 2020

DOI: https://doi.org/10.21203/rs.3.rs-127761/v1

License: (c) (1) This work is licensed under a Creative Commons Attribution 4.0 International License.

Read Full License 


\section{Abstract \\ Background}

The study was aim to prove that both rationality and emotion are indispensable for older people to maintain their ability to live independently during the twilight of their lives.

\section{Methods}

The resilience of older people to dementia were investigated by considering the interactions between educational levels and marriage status. Four sociodemographic variables (age, sex, educational level, and marital status) were collected from 1177 older Chinese participants, whose mini-mental state examination scores (MMSE scores) were measured.

\section{Results}

A lower educational level coupled with being widowed caused a greater risk for severe cognitive impairment (relative risk [RR] 1.48; 95\% confidence interval [Cl] 1.20-1.82; $p<0.001$ ) for high-aged older participants (age range: $\geq 80$ ) than for their low-aged counterparts (age range: $\geq 60$ and $<80$ ). In contrast, a higher educational level coupled with being married leveled this age-related risk for cognitive loss (RR $0.91 ; 95 \%$ Cl 0.65-1.27; $p=0.62$ ).

\section{Conclusions}

Further findings suggest that the synergistic influence of education and marriage was observed only among high-aged older people .Being both well-educated and married is associated with a delayed cognitive function for older people. However, longevity is a prerequisite for realizing this benefit.

\section{Background}

Benefiting from advances in science and technology, humans today have a higher probability of living longer than their predecessors [1]. However, in comparison to the acceleration of an aging population, they also have to face the challenges of increased morbidity, such as the dramatic increase in the number of dementia patients worldwide, which has essentially doubled every 20 years [2, 3]. It is urgent for global researchers to understand the pathological evolution of senile dementia to identify risk factors and develop preventive measures. The active management of senile dementia is necessary to ensure a sustainable future for human societies, since aging societies are an inevitable demographic trend [4].

Cognitive impairment and dementia make it difficult or impossible for older people to cope with daily activities. According to a hypothesis proposed by Stern [5], a relatively rich cognitive reserve is critical to 
understanding resiliency to the progressive evolution of the neuropathology of dementia. The factors contributing to the construction of an adequate cognitive reserve will help delay the onset of senile dementia, whereas a lack of these factors constitutes increasing risks. In addition to genetic factors [6], a growing number of modifiable factors have been related to senile dementia. These include occupational complexity $[7,8,9]$, educational attainment $[10,11,12]$, marital status [13], socioeconomic status [14], and social networks $[15,16,17,18]$.

Just recently, a data analysis report integrating six longitudinal studies demonstrated that older individuals with high educational attainment and high socioeconomic statuses have remarkably longer non-cognitively impaired life expectancies as opposed to those with low educational attainment and low socioeconomic statuses [19]. This observation suggests that education and socioeconomic status are synergistic resilience factors against the onset of senile dementia. Based on these implications, we sought to further explore the possibility of a synergistic effect on the risk for cognition loss through education and another resilience factor--marriage--among older people people. Compared to those possessing a higher socioeconomic status, it is considered normative for ordinary people to sustain a marriage-- which is regarded as one of the strongest interpersonal relationships in an individual's social network. Education can enable people to be more rational and make higher-quality decisions in their lives [20]. However, we should not ignore the strong emotional needs of older people [21]. In this study, we aim to prove that both rationality and emotion are indispensable for older people to maintain their ability to live independently during the twilight of their lives.

\section{Methods}

\section{Ethical statement}

Permission to conduct the study and to obtain entry for the purpose of gathering the data was obtained from the Ningbo College of Health Sciences Ethics Committee(NBWY-010). Prior to enrolment in the study, all participants or their guardians were informed of the research plan and signed a written statement of informed consent. The only prerequisite for a guardian to sign the informed consent statement on behalf of a participant was that the participant could not sign the consent form independently due to an impaired cognitive function. After completing the study, each participant received a gift worth less than 20 RMB.

\section{Participant characteristics}

From July 2018 to September 2018, our research team visited 5-level professional pension institutions to recruit older people aged 60 years or older. '5-level' implies that these facilities meet the highest level of care facility standards in China. The following inclusion criteria were used: (a) from local households and older than 60 years of age; (b) met the Diagnostic Criteria for Dementia (4th edition of the American Diagnostic and Statistical Manual of Mental Disorders). Mild cognitive impairment or severe cognitive impairment (SCl) were diagnosed in the clinic. 
For each participant, four sociodemographic variables (age, sex, educational level, and marital status) were collected by the researchers and verified by checking the electronic medical records of their respective professional pension institutions. All participants were divided into two groups by age: the lowaged older people group (age range: $\geq 60$ and $<80$ ) and the high-aged older people group (age range: $\geq 80$ ). Participants who were illiterate or had completed only elementary or junior high school education were classified as having low educational levels. Those who had completed high school or some college education were labeled as having a high educational level. Five distinct marital statuses of the subjects were recorded. These included single, widowed, divorced, married, and cohabitating with others. Accompanied by a trained researcher, each participant was required to complete the mini-mental state examination (MMSE)[22].

\section{Statistical analysis}

All data are expressed using the mean \pm SD (Standard Deviation). The software Graphpad Prism version 6.0 (GraphPad Software, Inc., La Jolla, CA, USA) was used to perform Fisher's exact test, followed by a calculation of the relative risk (RR) of $\mathrm{SCl}$, a Student's $t$-test, and a one-way analysis of variance (ANOVA) test. The abbreviation RR refers to the relative risk of being $\mathrm{SCl}$ in the high-aged group compared with that in the low-aged group. Differences were only considered to be significant at $p<0.05$.

\section{Results}

\section{The percentage of widowhood was significantly high among high-aged older people}

We collected sociodemographic information from a total of 1177 older Chinese people that were living in professional pension institutions and evaluated their cognitive functioning levels using the MMSE test (Table S1). More than $60 \%$ of the older people people were 80 years or older (Table 1 ). The MMSEevaluated cognitive functioning of the low-aged older people was noticeably better than that of the highaged counterparts $(p<0.001)$. There was no difference in the proportion of people with high education between the two groups. No participant reported their marital status as 'single', 'divorced', or 'cohabitating with others'. In the low-aged older people group, about $57 \%$ of the participants were widowed.

Comparably, seven of ten high-aged older people people were widowed. A significant difference between the two groups was noted in this percentage $(p<0.001)$. We did not find a gender-specific difference in the percentage of widowed people within the high-aged older people group. The percentage of widowed men was $70.7 \%$, and the percentage of widowed women was $71.8 \%$.

\section{Higher educational level and being married decreased the age-related risk for severe cognitive impairment}

We evaluated the influence of education and marriage on the incidence of severe cognitive impairment. Widowhood rather than being married significantly increased the age-related risk for severe cognitive impairment (RR 1.46; 95\% confidence interval [CI] 1.23-1.74; $p<0.001$, Table 2). Compared with welleducated older people people, poorly educated older people had a higher age-related risk for severe cognitive impairment (RR 1.36; 95\% Cl 1.17-1.59; $p<0.001$, Table 3 ). When education and marriage were 
assessed jointly, the age-related risk for severe cognitive impairment was completely offset by a higher educational level coupled with being married (RR 0.91; 95\% Cl 0.65-1.27; $p=0.67$, Table 4). However, poorly educated and widowed older people had the highest age-related risk for severe cognitive impairment (RR 1.48; 95\% Cl 1.20-1.82; $p<0.001$, Table 4).

\section{Well-educated and married high-aged older people appear resilient to senile dementia}

To assess the cognitive impact of education and marriage, participants were further divided into four subgroups: low educational level and widowed (LW), low educational level and married (LM), high educational level and widowed (HW), and high educational level and married (HM). No significant difference was observed in the MMSE score among the four subgroups of low-aged older people (Fig. 1A). Comparably, the mean MMSE score of HM older people was obviously higher than that of the LW counterparts ( $p<0.01$, Fig. 1B). Further comparisons between the corresponding subgroups in the two age groups revealed obvious age-related cognitive decline in LW, LM, and HW older people compared to HM older people.

\section{Discussion}

By dividing the participants recruited for this study into two groups, significant differences were observed in the proportion of widowed people rather than in the proportion of those with high levels of education. Consistent with previous studies in the United States and South Korea [23,24], our findings suggest a higher risk for severe cognitive impairment among unmarried older people as opposed to those who are married. In our study, only one of the three most common unmarried statuses (single, divorced, and widowed) was investigated since our survey indicated that single and divorced older peoplewere rare compared to those who were widowed. Using the incidence rates for mild cognitive impairment among older married individuals as a baseline, Brenowitz and his colleagues found that only the widowed-rather than the single or divorced--held a significant risk for mild cognitive impairment [25]. Therefore, it is reasonable to suggest that widowed older people should be investigated separately rather than in conjunction with those who are single or divorced. Despite women having longer life expectancies than men [26], we found that high-aged older people men and women had similar high widowhood rates. This finding suggests that it is more difficult to continue marriage at an advanced age than to extend the life of high-aged older people individuals. Therefore, marital status is more important for the maintenance of their cognitive ability in comparison to younger older people.

For older people with mild cognitive impairment, living in a professional pension institution is not as costeffective as living at home [27]. However, we learned through dialogue that avoiding becoming a burden to their children, rather than economic efficiency, was the primary reason governing older people's decision to choose institutional care. Concern over cognitive decline is the leading reason behind older people choosing institutional care [28]. Our observations indicate that the cognitive functioning of the older people living in professional pension institutions was generally poor. This finding is consistent with the assertions of Werner and Segel-Karpas, who noted that signs of dementia caused older people to 
worry about dementia and adopt this uneconomical behavior[28]. Other possible explanations for this is that a residential shift from familiar surroundings to an unfamiliar place might have a negative impact on cognitive functioning [29]. Subsequently, the weak interpersonal relationships established in institutions can hardly replace the strong emotional support that comes from marriage. The substitution of a strong interpersonal relationship with multiple weak interpersonal relationships has been demonstrated as being harmful to cognitive functioning [25]. Nevertheless, our results suggest that maintaining one's married status in old age is beneficial to maintaining cognition in comparison to being widowed, even if there are deficiencies in professional pension institutions.

Results of a recent study show that cognitive decline is not inevitable among at-risk older people persons if continuous lifestyle interventions can be adopted [30]. Compared to other high-aged people, married high-aged participants with high levels of education were identified as having a lower risk for severe cognitive impairment. This finding was consistent with previous studies [31,32]. Segmentation of the participants implies that married low-aged older people with high levels of education have the lowest risk of suffering from severe cognitive impairment when they are over 80 years old. Our results suggest that in this subpopulation, the demographical indicators of education and marriage demonstrate a synergistic prevention pattern against severe cognitive impairment. However, it should be noted that this lower risk was only the result of their comparison to the high-aged group. Compared to other people in the low-aged group, these people did not show a lower rate of severe cognitive impairment.

There are some limitations to this study. First, the sample size of this study is small. It only focused on the older people people living in professional pension institutions and did not investigate the older people living at home. Therefore, the main conclusion identifying an age-related education-marriage synergetic relationship should be considered with caution and requires further validation by larger-scale panel studies. Second, clinical diagnoses of severe cognitive impairment were not used in the study. Relying solely on the MMSE measures may possibly result in the misclassification of research participants. Third, because this is a cross-sectional study, it is difficult to determine the exact role of education-marriage synergy in delaying cognitive decline in older people people from the perspective of individualization. Fourth, additional factors related to cognitive decline, including cardiovascular and cerebrovascular diseases, tobacco and alcohol use, and lifestyle, were not evaluated or used for data segmentation in this study.

\section{Conclusions}

This cross-sectional study reveals that education alone does not sufficiently address the complexity of the risk factors against age-related cognitive decline. Maintaining the integrity of marriage is also necessary for ensuring behavioral independence in the twilight of older life. This age-related synergy between education and marriage against cognitive decline suggests that a stable and strong interpersonal relationship is important for the growing subpopulation of long-lived older people with high levels of education. The benefits of marriage become more apparent as people age. Further comparative studies are needed to investigate the potential impact of this trend on senile dementia. 


\section{Abbreviations}

MMSE: mini-mental state examination

\section{Declarations}

\section{Ethics approval and consent to participate}

The ethics committee of the college(NBWY-010) approved this study. Prior to enrolment in the study, all participants or their guardians were informed of the research plan and signed a written statement of informed consent.

\section{Consent for publication}

Not applicable.

\section{Availability of data and materials}

All data generated or analyzed during this study are included in this published article and its supplementary information files.

\section{Competing interests}

The authors declare that they have no competing interests.

\section{Funding}

This work was supported by National Natural Science Foundation of China (No.71774092), Zhejiang Philosophy and Social Science Planning Project(No.19NDJC121YB), and Zhejiang Public Welfare Technology Application Research Project(No.LGF19H260008). The funders had no role in study design, data collection and analysis, decision to publish, or preparation of the manuscript.

\section{Authors' contributions}

NS and RC $\mathrm{J}$ conception, design, analysis and interpretation of data, drafting the manuscript, revising manuscript, final approval; CY G acquisition of data, project administration, revising manuscript, final approval; TD S formal analysis, revising manuscript, final approval; XX D conception, revising manuscript, final approval; $L$ L \& P Yconception, design, funding acquisition, revising manuscript, final approval. All authors read and approved the final manuscript.

\section{Acknowledgment}

The authors would like to thank the dementia elderly who participated in the study.

\section{References}


1. Partridge L, Deelen J, Slagboom PE. 2018. Facing up to the global challenges of ageing. Nature. 2018;561(7721):45-56.

2. Ferri $C P$, Prince M, Brayne C, Brodaty H, Fratiglioni L, Ganguli M, et al. Global prevalence of dementia: a Delphi consensus study. Lancet. 2005;366(9503):2112-7.

3. Prince M, Bryce R, Albanese E, Wimo A, Ribeiro W, Ferri CP. 2013. The global prevalence of dementia: a systematic review and metaanalysis. Alzheimers Dement. 2013;9(1):63-75.e2.

4. Götmark F, Cafaro P, O'Sullivan J. Aging Human Populations: Good for Us, Good for the Earth. Trends Ecol Evol. 2018;33(11):851-62.

5. Stern Y. What is cognitive reserve? Theory and research application of the reserve concept. J Int Neuropsychol Soc. 2002;8(3):448-60.

6. Haan MN, Shemanski L, Jagust WJ, Manolio TA, Kuller L. The role of APOE epsilon4 in modulating effects of other risk factors for cognitive decline in older people persons. JAMA. 1999;282(1):40-6.

7. Qiu C, Karp A, von Strauss E, Winblad B, Fratiglioni L, Bellander T. Lifetime principal occupation and risk of Alzheimer's disease in the Kungsholmen project. Am J Ind Med. 2003;43(2):204-11.

8. Karp A, Andel R, Parker MG, Wang HX, Winblad B, Fratiglioni L. Mentally stimulating activities at work during midlife and dementia risk after age 75: follow-up study from the Kungsholmen Project. Am J Geriatr Psychiatry. 2009;17(3):227-36.

9. Wajman JR, Bertolucci PHFF. Intelectual demand and formal education as cognitive protection factors in Alzheimer's disease. Dement Neuropsychol. 2010;4(4):320-4.

10. Allegri RF, Taragano FE, Krupitzki H, Serrano CM, Dillon C, Sarasola D, et al. Role of cognitive reserve in progression from mild cognitive impairment to dementia. Dement Neuropsychol. 2010;4(1):28-34.

11. Terrera GM, Minett T, Brayne C, Matthews FE. Education associated with a delayed onset of terminal decline. Age Ageing. 2014;43(1):26-31.

12. Robitaille A, van den Hout A, Machado RJM, Bennett DA, Čukić I, Deary IJ, et al. Transitions across cognitive states and death among older adults in relation to education: A multistate survival model using data from six longitudinal studies. Alzheimers Dement. 2018;14(4):462-72.

13. Håkansson K, Rovio S, Helkala EL, Vilska AR, Winblad B, Soininen H, et al. Association between midlife marital status and cognitive function in later life: population based cohort study. BMJ. 2009;339:b2462.

14. Osler M, Avlund K, Mortensen EL. Socio-economic position early in life, cognitive development and cognitive change from young adulthood to middle age. Eur J Public Health. 2013;23(6):974-80.

15. Bassuk SS, Glass TA, Berkman LF. Social disengagement and incident cognitive decline in community-dwelling older people persons. Ann Intern Med. 1999;131(3):165-73.

16. Fratiglioni L, Paillard-Borg S, Winblad B. An active and socially integrated lifestyle in late life might protect against dementia. Lancet Neurol. 2004;3(6):343-53.

17. Saczynski JS, Pfeifer LA, Masaki K, Korf ES, Laurin D, White L, et al. The effect of social engagement on incident dementia: the Honolulu-Asia Aging Study. Am J Epidemiol. 2006;163(5):433-40. 
18. Kuiper JS, Zuidersma M, Oude Voshaar RC, Zuidema SU, van den Heuvel ER, Stolk RP, et al. Social relationships and risk of dementia: A systematic review and meta-analysis of longitudinal cohort studies. Ageing Res Rev. 2015;22:39-57.

19. Robitaille A, van den Hout A, Machado RJM, Bennett DA, Čukić I, Deary IJ, et al. Transitions across cognitive states and death among older adults in relation to education: A multistate survival model using data from six longitudinal studies. Alzheimers Dement. 2018;14(4):462-72.

20. Kim HB, Choi S, Kim B, Pop-Eleches C. The role of education interventions in improving economic rationality. 2018;362(6410):83-86.

21. van der Steen JT, Smaling HJ, van der Wouden JC, Bruinsma MS, Scholten RJ, Vink AC. Music-based therapeutic interventions for people with dementia. Cochrane Database Syst Rev. 2018;7:CD003477.

22. Folstein MF, Folstein SE, McHugh PR. "Mini-mental state". A practical method for grading the cognitive state of patients for the clinician. J Psychiatr Res. 1975;12(3):189-98.

23. Steenland K, MacNeil J, Vega I, Levey A. Recent trends in Alzheimer disease mortality in the United States, 1999 to 2004. Alzheimer Dis Assoc Disord. 2009;23(2):1165-70.

24. Bae JB, Kim YJ, Han JW, Kim TH, Park JH, Lee SB, et al. Incidence of and risk factors for Alzheimer's disease and mild cognitive impairment in Korean older people. Dement Geriatr Cogn Disord. 2015;39(1-2):105-15.

25. Brenowitz WD, Kukull WA, Beresford SA, Monsell SE, Williams EC. Social relationships and risk of incident mild cognitive impairment in U.S. Alzheimer's disease centers. Alzheimer Dis Assoc Disord. 2014;28(3):253-60.

26. Fei FR, Zhong JM, Yu M, Gong WW, Wang M, Pan J, et al. Impact of injury-related mortality on life expectancy in Zhejiang, China based on death and population surveillance data. BMC Public Health. 2017;18(1):24.

27. Kraft E, Marti M, Werner S, Sommer H. Cost of dementia in Switzerland. Swiss Medical Weekly Swiss Med Wkly. 2010;140:w13093.

28. Werner P, Segel-Karpas D. Factors Associated With Preferences for Institutionalized Care in older people Persons: Comparing Hypothetical Conditions of Permanent Disability and Alzheimer's Disease. J Appl Gerontol. 2016;35(4):444-64.

29. Fong TG, Jones RN, Marcantonio ER, Tommet D, Gross AL, Habtemariam D, et al. Adverse outcomes after hospitalization and delirium in persons with Alzheimer disease. Ann Intern Med. 2012;156(12):848-56.

30. Kulmala J, Ngandu T, Havulinna S, Levälahti E, Lehtisalo J, Solomon A, et al. The Effect of Multidomain Lifestyle Intervention on Daily Functioning in Older People. J Am Geriatr Soc. 2019;67(6):1138-44.

31. Larsson SC, Traylor M, Malik R, Dichgans M, Burgess S, Markus HS, et al. Modifiable pathways in Alzheimer's disease: Mendelian randomisation analysis. BMJ. 2017;359:j5375.

32. Wolf D, Fischer FU, Fellgiebel A. Alzheimer's Disease Neuroimaging Initiative. A methodological approach to studying resilience mechanisms: demonstration of utility in age and Alzheimer's 
disease-related brain pathology. Brain Imaging Behav. 2019;13(1):162-71.

\section{Tables}

Table 1

Participant characteristics.

\begin{tabular}{|lll|}
\hline Characteristics & Low age $(\mathbf{n}=\mathbf{4 3 2})$ & High age $(\mathbf{n}=\mathbf{7 4 5})$ \\
\hline Age (years) mean (SD) & $71.5(5.6)$ & $86.9(4.7)$ \\
\hline Sex (male/female, $\mathrm{n})$ & $223 / 209$ & $278 / 467$ \\
\hline Educational level (low/high, $\mathrm{n})$ & $297 / 135$ & $532 / 213$ \\
\hline Marital status (widowed/married, $\mathrm{n})$ & $246 / 186$ & $529 / 216$ \\
\hline MMSE score (mean, SD) & $7.8(9.0)$ & $5.1(7.3)$ \\
\hline
\end{tabular}

Table 2

Influence of marriage on the incidence of severe cognitive impairment.

\begin{tabular}{|lllll|}
\hline Marital status & Low age (SCl/non-SCl) & High age $(\mathrm{SCl} / \mathrm{non}-\mathrm{SCl})$ & $\mathrm{RR}(95 \% \mathrm{Cl})$ & $\boldsymbol{p}$ value \\
\hline Widowed & $95 / 151$ & $298 / 231$ & $1.46(1.23-1.74)$ & $<0.001$ \\
\hline Married & $89 / 97$ & $115 / 101$ & $1.11(0.92-1.35)$ & 0.32 \\
\hline SCl: severe cognitive impairment. & & & \\
\hline
\end{tabular}

Table 3

Influence of education on the incidence of severe cognitive impairment.

\begin{tabular}{|lllll|}
\hline $\begin{array}{l}\text { Educational } \\
\text { level }\end{array}$ & Low age (SCl/non-SCI) & High age (SCl/non-SCl) & RR (95\% Cl) & p value \\
\hline Low & $122 / 175$ & $298 / 234$ & & \\
\hline High & $62 / 73$ & $115 / 101$ & $1.36(1.17-1.59)$ & $<0.001$ \\
\hline SCl: severe cognitive impairment. & & $1.18(0.94-1.47)$ & 0.15 \\
\hline
\end{tabular}


Table 4

Joint influence of marriage and education on the incidence of severe cognitive impairment.

\begin{tabular}{|lllll|}
\hline $\begin{array}{l}\text { Marital status /Educational } \\
\text { level }\end{array}$ & $\begin{array}{l}\text { Low age (SCl/non- } \\
\text { SCl) }\end{array}$ & $\begin{array}{l}\text { High age (SCl/non- } \\
\text { SCl) }\end{array}$ & RR (95\% Cl) & $\begin{array}{l}p \\
\text { value }\end{array}$ \\
\hline Widowed/Low & $67 / 111$ & $218 / 174$ & $1.48(1.20-$ & $<$ \\
& & & $1.82)$ & 0.001 \\
Married/High & $34 / 33$ & $35 / 41$ & $0.91(0.65-$ & 0.62 \\
\hline
\end{tabular}

SCl: severe cognitive impairment.

Figures 
A
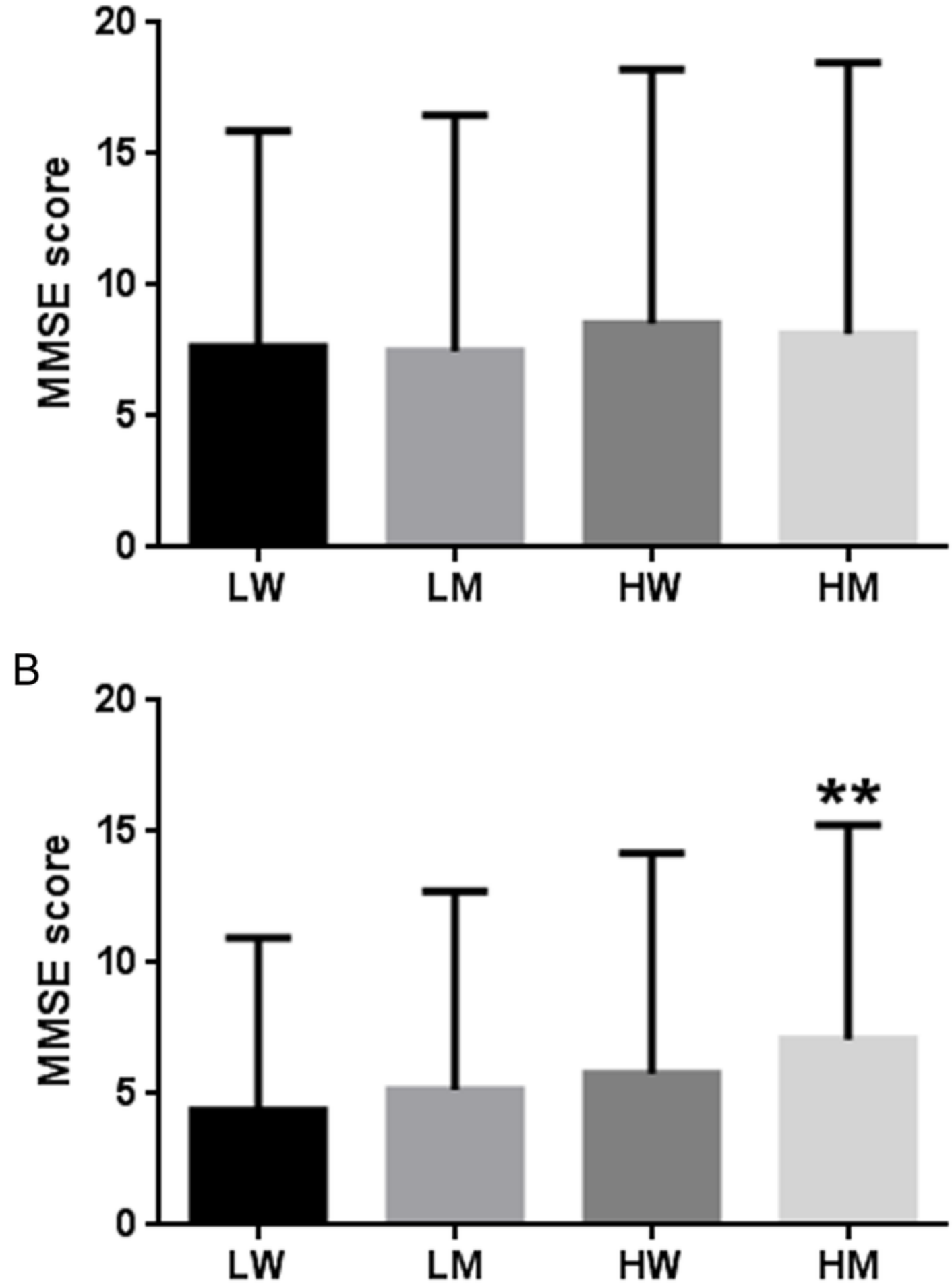

Figure 1

No significant difference was observed in the MMSE score among the four subgroups of low-aged older people (Fig. 1A). Comparably, the mean MMSE score of HM older people was obviously higher than that of the LW counterparts ( $p<0.01$, Fig. 1B). Further comparisons between the corresponding subgroups in the two age groups revealed obvious age-related cognitive decline in LW, LM, and HW older people compared to HM older people. 